\title{
Brittany Spaniel
}

National Cancer Institute

\section{Source}

National Cancer Institute. Brittany Spaniel. NCI Thesaurus. Code C53879.

The Brittany is a vigorous, medium-sized, leggy dog with a fairly short, lightly feathered single coat. Coat color may be orange and white, liver and white, black and white, liver tricolor, and black tricolor. The high-set ears are rather short in a triangular shape, slightly fringed and hanging close to the head. Height: 17-21 inches (43-53 cm.) Weight: 30-40 pounds (14-18 kg.) 